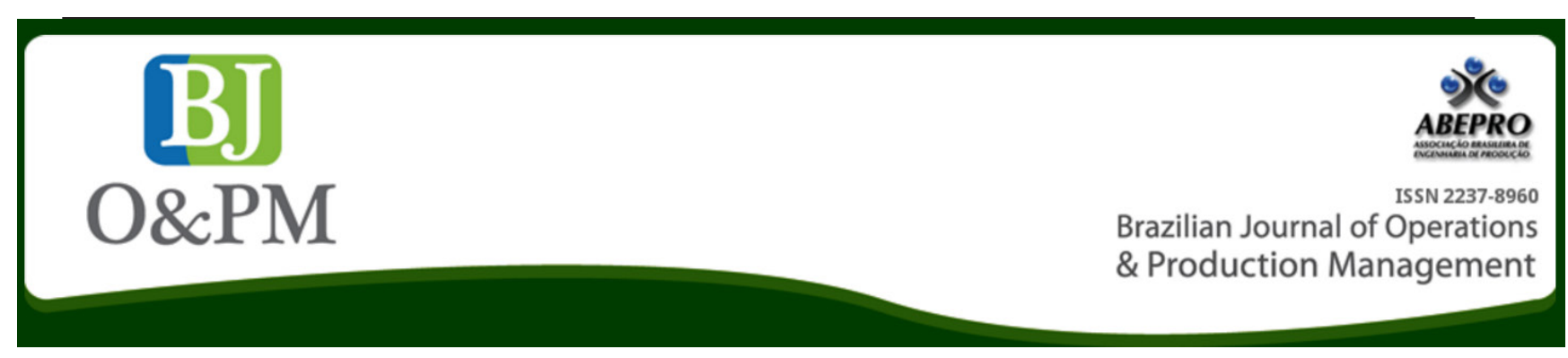

\title{
USING COST-VOLUME-PROFIT TO ANALYSE THE VIABILITY OF IMPLEMENTING A NEW DISTRIBUTION CENTER
}

\author{
Ana Paula Beck da Silva Etges ${ }^{a}$; Rafael Calegaria; Marisa Ignez dos Santos Rhoden ${ }^{a}$; Marcelo Nogueira Cortimiglia ${ }^{a}$ \\ ${ }^{\text {a }}$ Federal University of Rio Grande do Sul (UFRGS) - Porto Alegre, RS, Brazil
}

\begin{abstract}
Firms are constantly improving their activities in order to become more competitive. With the diffusion of international competition and easier access to global markets, effective logistic and inventory management strategies become essential to all players. In this sense, there is a clear tradeoff between inventory costs and service level. A common strategy to address this issue is to locate distribution centers (DC) near key markets. However, the decision to build new DCs must be supported by clear and convincing analysis. In this context, this paper reports the use of cost-volume-profit analysis to assess the viability of establishing a new DC by a real company that manufactures radiopharmaceutical products. The researchers collected and analysed detailed financial information from the company and compared the current scenario with potential future scenarios using the cost-volume-profit technique. Next, expected firm profitability is compared for two scenarios: with and without the new DC.
\end{abstract}

Palavras-chave: Cost-volume-profit; decision making; logistic costs; radiopharmeceutical distribution.

\section{INTRODUCTION}

The main objective of the logistic function is to provide a firm's customers with the right product, at the right place and right time, according to pre-determined conditions (Ballou, 1999). In this context, a few key logistic activities are considered strategic, especially in a country of continental dimensions as Brazil. For instance, it is essential that logistic activities such as transportation and inventory managegement operate with efficiency so that product delivery is not hindered (Fernandes et al., 2011).

However, given the complexity inerent to the logistic processes, it is difficult to estimate optimal transportation and warehousing costs (Engblom et al., 2012). According to Yoshizaki (2002), the higher the availability of material (which results in a higher service level), the higher the inventory carrying costs. On the other hand, increased availability reduces opportunity costs related to sales lost because of stockout. The same author posits that as the number of warehouses increases, service level improves and delivery costs decrease, but at the expense of increased (fixed) warehousing costs. Thus, a complex tradeoff in distribution management is evident. A common approach to address this tradeoff is to build distribution centers (DC) close to key markets in order to improve the service level perceived by the customer, reduce lead time and logistic costs, increase market share, and, eventually, facilitate entry in new markets and achieve higher competitiveness levels (Hill, 2003).

However, even if the variable part logistic costs are reduced with this strategy, it is important to analyse the remaining cost components (Waller et Fawcett, 2012), given that a company must aspire to reduce the total logistic cost, and not only local costs (Stock et Lambert, 2001). Waller and Fawcett (2012) explored the complexity that charcterizes the decision to build a new distribution center and concluded that distribution costs are not usually known a priori, even if cost modelling techniques are used, since models can be affected by numerous endogenous and uncertain variables, many of which are not static.

Among the techniques used to analyse production objectives that enable cost recovery and the onset of 
profitability, the cost-volume-profit (CVP) method stands out. CVP analysis is already established in comparative studies of a firm's relationship with the external environment (Ravichandran, 1993). To Horngren et al., (2000), CVP analysis provides a comprehensive financial picture of a given scenario and helps to estimate how revenues, costs, and profits behave as business activities, product prices or fixed commercialization costs change. Among the benefits associated with CPV, Moraes et Wernke (2006) cite the support to decision-making about which specific items should be offered for sale and if any productive segment should be abandoned during the evaluation of alternative scenarios of promotions and price reductions. CVP analysis also allows a better understanding of safety margins, which consist in excess sales above the point of equilibrium (Bornia, 2010). Consequently, it is possible to estimate how much the sales can decrease without real harm to the firm's long term financial viability.

In this context, this paper reports the use of cost-volumeprofit analysis to assess the viability of building a new DC by a Brazilian company that manufactures radiopharmaceutical products. The firm operates in the city of Porto Alegre and evaluated the opportunity to establish a DC in São Paulo. Initially, the researchers collected financial data to support a CVP analysis that determined the minimum sales level required to support the new DC. Thus, it was possible to estimate the financial effects of establishing the new DC, enriching firm managers' decision-making.

\section{LITERATURE REVIEW}

The logistic cost analysis is essential for the logistic function. An organization must regard essential to analyse the reduction of logistic global cost and not only the local cost (STOCK; LABERT, 2001). Ballou (1999) shows that the logistic costs are central for the logistic system.

The inclusion of the logistic term in the literature is not disseminated. Gudehus et Kotzab (2009) argue that the explanation for this exclusion is that the companies do not define the logistic costs in the correct way. And because of that, companies cannot compare the logistic cost performance even when are from the same business market.

Engblom et al., (2012) presented a model where is done an analysis about the logistic costs and show a 6 variable model: transportation costs, storage costs, handling cost, management cost, packing cost and indirect costs. Another different kind of costs associated with logistic are presented by Gudehus et Kotzab (2009) in eleven subdivisions: i) personal costs; ii) space and area; iii) route; iv) logistics equipment; v) loading costs; vi) costs of materials used in logistics; vii) IT costs; viii) third party costs; ix) costs of taxes; $\mathrm{x}$ ) planning costs; and xi) material storage costs.
Not only the cost mensuration is complex, but the modelation is difficult. This is justified by the fact that costs that has unknown relationship with the decision variables. Waller et Fawcett (2012) explans that a deployment decision of a new distribution center and the costs associated with the distribution process are not fully understood. Issues such as inbound and outbound freight type, inventory costs, labor costs and other factors may change over the period analyzed.

The difficulties for making a prevision of the transportation frequence are limited as well as the hability to forecast changes in this prevision. When the metric cost is considered the complexity is higher, because each change represents a cost variability that must be evaluated in an economic way and is influenced by different variables in different intensity (Waller et Fawcett 2012)

The Cost Volume Profit Analysis (CVP) is a model that has spread in the comparative study of the relationship of a firm and its environment (Ravichandran, 1993). For Horngren et al., (2000) analysis of CVP provides a wide financial view of a given scenario and assists in examining the behavior of revenues, costs and profits as there is an alteration in the level of activity of a business, the sale price of products or fixed-cost linked to their marketing. It presents a common use for viewing the breakeven point for an operation, ie.,, the volume that amortizes the financial expenditures of the company. To carry out this type of analysis is necessary to understand the workings of the CVP function.

The composition of the CVP function has as basic variables fixed costs and contribution margin. The breakeven point is given by the ratio of fixed costs and its margin of contribution. Bornia (2010) presents the calculation to obtain the contribution margin, Equation 1.

\section{$C M=$ Unitary Sale Price - Unitary Variable Cost}

Among the benefits provided by the use of CVP, Moraes et Wernke (2006) list the aid in decision making about which items should be on general sale and if any segment production could be abandoned with the aim of promote another by the change in the contribution margin. The CVP analysis also allows the understanding of security margins, which can be represented by an excess of the company's sales on its balance point. Consequently, the analisys inform, how sales can fall without prejudice to the company. Another benefit of CVP analisys is linked to the shutdown point. Bornia (2010) induces the concept of shutdown point is especially true for analysis of the decision to remove or not a product or a product line. It is performed primarily by reason of clearable costs on the unit contribution margin.

The clearable fixed costs will be specific to the product (or product line), while non-clearable fixed costs correspond 
to the share of the common fixed costs of the company that are allocated (or absorbed) to this product (or this line of products). If the product cover their specific fixed costs and give a contribution to fixed cost common where it is allocated, it will not be disabled in the short term (in the long term, the company could reduce its total fixed costs by reducing the share of fixed costs that is allocated to the product analised.)

Considering the literary discussion about the importance of logistics costs and feasibility of using CVP tool to aid decision making, it is presented in the following sections a study applied based on the concepts presented.

\section{METHODOLOGY}

In order to achieve the research objective, which requires a detailed investigation of a single setting, a case study research strategy was employed. The research is applied, since it aims to generate useful solutions for all involved. Besides, a hands-on, easy-to-use methodological approach was chosen, which can be easily transferred to practitioners at the company studied.

In order to investigate the viability of establishing a new DC, a three-step empirical study involving financial analysis tools was conducted. During the study, the researchers maintained constant contact with the studied company. This facilitated data collection and validation of every single step in the analysis and provided the firm with instant feedback.

The first step in the empirical research involved a comprehensive analysis of the firm structure, strategy and operations. It also involved the understanding of the peculiarities of the market where the firm operates, with special attention dedicated to transportation activities. This was done through a series of interviews with top and middle-level managers responsible for the following areas: quality control, R\&D, warehousing, accounting and auditing, procurement, financial planning and strategic management. The semi-structured interviews took place during two days; on average, the interviews were 45 minutes long.

The second step in the empirical research was the collection and analysis of financial data, sales forecasting, past sales data by geographical region, and regulatory compliance data. This data was collected partially during the aforementioned interviews, but also through analysis of firms' documents and records. This data substantiated the financial analysis using the CVP technique that defined the minimum sales level for each product that would justify, from a financial point of view, the establishment of the new DC in São Paulo.

Given the financial criteria obtained in step two, the third step in the empirical research involved the decision-making, by the firm top management, supported by the analysis of the possible effects of a new DC. Finally, the results were compilled and presented to the firm managers.

\section{RESULTS AND DISCUSSION}

\subsection{Case description}

The firm investigated is ten years old and is member of a university technology park, where the management offices and production line are located. The firm also has a commercial office in São Paulo, which is responsible for approximately $25 \%$ of the total sales revenues. It manufactures and distributes radiopharmaceutical products, a high-value supply for medical imaging diagnosis systems such as PET scans. The firm has two main business lines: products and services. Most revenues come from products: the firm has a portfolio of nine products, but $73 \%$ of the overall revenues come from a single product. The very specific nature of the firms' products require significant $R \& D$, production, distribution, and sales capabilities.

It must be noted that the Brazilian radiopharmaceutical industry is very peculiar, especially because it is characterized by a very low number of participants. In fact, the studied company is the only private firm that operates in the Brazilian market. Moreover, radioactive tracers are subjected to strict regulatory oversight and constant monitoring by the Federal agency that deals with drugs and medications.

It is also important to highlight the studied firm's declared innovation-oriented strategy, which translates to substantial investments in R\&D activities, especially in partnership with foreign players. Since its inception, the firm has established a large network of foreign partners such as universities, research institutes, and similar companies operating in international markets. The studied firm is the undisputed leader in the radiopharmaceutical Brazilian market. Thus, it can be noticed that the firm is a strong advocate of internationalization, as most of the firms' products are national versions of products already commercialized in other countries.

\subsection{Interviews}

Considering this step as the starting point to understand the setting, three researchers spent two whole days embedded in the company. Interviews were conducted with middle and top managers responsible for the following areas: quality control, R\&D, warehousing, accounting and auditing, procurement, financial planning and strategic management.

Specifically regarding the R\&D team, the researchers investigated the strict regulatory setting that impacts the 
Brazilian Journal of Operations \& Production Management Volume 13, Número 1, 2016, pp. 44-50 DOI: 10.14488/BJOPM.2016.v13.n1.a4

firm. Among these, a specific financial cost was identified: the firm must keep a trained pharmacist at the new DC to comply with regulatory requirements. Another example of unforeseen costs involves transportation within São Paulo. Instead of vans or cars, the firm has explored the option of hiring motocycle drivers. However, the regulatory agency requires that these professionals must be specifically trained and certified to handle the radiopharmaceutical products; the estimated cost of such training was added to the analysis. It was also pointed out that the DC has to be equipped with refrigeration facilities.

The warehousing team, on the other hand, emphasized the need for a detailed study to design the layout of the potential new DC. The space should be adequate to the product volumes to be handled but should also comply with regulatory guidelines for warehousing health commodities. These include minimum volume and space requirements for staging and storing commodities, special racking systems and material handling equipment, and a certified warehouse management system. Eventually, even interchangeable shipment and receiving staging areas could prove necessary. These requirements were factored in the financial analysis.

Additionally, the financial team provided the researchers with full access to firm's balance sheets, whereby it was possible to structure the CVP analysis. The financial team also explained the current financial management strategy and its operational directives, particularly regarding cost estimation methods and the working definition of fixed and variable costs used by the company.

Finally, the top management was fully available to explain the firm's general strategy and its deployment in short-term operational plans. The top management was able to aggregate valuable qualitative information such as a critical appraisal regarding current and prospective key clients (and their locations), goals for shortening delivery time, company relationship with regulatory agencies, universities, research institutes, competitors and customers, and financial availability for the prospected new DC. The top managmenet team also promptly questioned and validated most of the non-financial premises behind the CVP analysis.

\subsection{CVP Analysis}

The CVP analysis was conducted in order to estimate the sales volume, for each product, necessary to justify the establishment of a DC in São Paulo, one of the key markets for the company. The premise for a new DC is that it can reduce variable logistic costs, but at the expense of higher fixed logistic costs associated with an expanded physical infrastructure.

The first step in the CVP analysis was to assess how each product contributes to overall revenues and the main customers (along their geographical location) for each product. It was found that the product portfolio contains 9 items, whose sales are distributed as follows: $22 \%$ in the Southern region (RSU), 26\% in São Paulo (RSP), 23\% in the other Southeaster states, that is, MG, RJ and ES (DRSE), and $28 \%$ distributed in the remaining regions.

Next, the researchers listed the price of each product and estimated variable costs associated with each product based on past sales from January to November 2014. The average price for each product was calculated for that period and used in the calculations as the product price. Variable costs considered the price of raw materials for each product, the direct labour costs associated with the production of each product, and the estimated logistic cost for each product. The estimation of logistic costs required the calculation of the average sizes of shipped lots: the global expenditures with logistic activities for each product were summed up and, considering the period under analysis, divided by the average number of products shipped per order per region was calculated and rounded up to the next whole number. All partial results were validated with the company. Then, the difference between variable costs required keeping the logistic activites in Porto Alegre only and the estimated variable costs for establishing the new DC in São Paulo were analysed. This difference will impact the Unitary Contribution Margin and the Equilibrium Revenue for products in both regions. The collected data are illustrated in Table 1.

At this point in the analysis, given that the studied firm has a diversified product portfolio and both the share of revenue for each product at each region and Equilibrium Revenue, the Unitary Contribution Ration for the two scenarios was calculated: 0.79 for the current situation and 0.82 for the scenario with the new DC in São Paulo.

The analysis followed with the compilation of current fixed costs and the estimation of the costs associated with the establishment of the necessary physical infrastructure for the new DC. The costs for the current structure were obtained directly from the firms' balance sheets, and amounted to $R \$ 5,669,044.60$. The expense items associated with the new DC were estimated as follows: monthly rental for a medium-sized warehouse with cold and clean storage facilities in different industrial districts in São Paulo, labour costs for a pharmacist and warehouse staff trained to operate health supplies, monthly logistic costs for shipping products from the manufacturing center (in Porto Alegre) to the new DC, one-time construction costs to adapt a common warehouse to handle health supplies in compliance with local regulatory guidelines. The fixed costs for the new DC amounted to $\mathrm{R} \$ 558,045.84$ for the same period (JanuaryNovember), of which $\mathrm{R} \$ 32,000.00$ amount to one-time investments, while the rest represent monthly expenses of $R \$ 50,731,44$. It is interesting to note that the current fixed structure in Porto Alegre would remain, and this additional 
amount to the current fixed cost. Then the total fixed cost for the new DC amounted $R \$ 6,259,090.44$. Using the fixed cost of each region, and the distribution of sales by region and product, is possible to calculate the Equilibrium income of each sold product in each region and in the sequence the Equilibrium Point in volume or units that must be sale. With the sum of all the incomes is possible to estimate the equilibrium income of each dc in analysis. Table 2 illustrates the calculation of the equilibrium points of each product for all regions.

Table 1 - Data detailing

\begin{tabular}{|c|c|c|c|c|}
\hline \multicolumn{5}{|c|}{ Average size of shipped lots } \\
\hline Consolidated & RSU & RSP & DRSE & DRB \\
\hline A & 6,00 & 6,00 & 6,00 & 5,00 \\
\hline B & 4,00 & 4,00 & 4,00 & 3,00 \\
\hline C & 1,00 & 2,00 & 1,00 & 1,00 \\
\hline $\mathrm{D}$ & 2,00 & 2,00 & 2,00 & 2,00 \\
\hline E & 2,00 & 2,00 & 2,00 & 2,00 \\
\hline $\mathrm{F}$ & 1,00 & 1,00 & 1,00 & 1,00 \\
\hline G & 1,00 & 1,00 & 1,00 & 1,00 \\
\hline $\mathrm{H}$ & 3,00 & 2,00 & 2,00 & 2,00 \\
\hline I & $\begin{array}{r}1,00 \\
\end{array}$ & 1,00 & 1,00 & 1,00 \\
\hline \multicolumn{3}{|c|}{$\%$ of income from each region } & & \\
\hline RSU & RS $\quad 2,465.484,06$ & $22 \%$ & & \\
\hline RSP & RS $2.849 .488,40$ & $26 \%$ & & \\
\hline DRSE & RS $2.557 .162,50$ & $23 \%$ & & \\
\hline \multirow[t]{2}{*}{ DRB } & $\begin{array}{ll}\text { RS } & 3,133,703,73\end{array}$ & $28 \%$ & & \\
\hline & $\begin{array}{|ll|}\text { RS } \quad 11.005 .838 .69 \\
\end{array}$ & & & \\
\hline \multicolumn{3}{|c|}{$\%$ of income of each product } & & \\
\hline A & RS $8.047 .244,05$ & $73 \%$ & & \\
\hline$B$ & $750.511,10$ & $7 \%$ & & \\
\hline C & $197,433,69$ & $2 \%$ & & \\
\hline D & $251.805,45$ & $2 \%$ & & \\
\hline E & $237.784,85$ & $2 \%$ & & \\
\hline$F$ & $22,679,80$ & $0 \%$ & & \\
\hline G & $619.789,80$ & $6 \%$ & & \\
\hline $\mathrm{H}$ & $869.910,00$ & $8 \%$ & & \\
\hline 1 & RS $\quad 20.504,95$ & $0 \%$ & & \\
\hline TOTAL & RS $11.017 .663,69$ & & & \\
\hline \multicolumn{2}{|c|}{ Averave Price } & & & \\
\hline A & 604,03 & & & \\
\hline B & 113,37 & & & \\
\hline C & 118,91 & & & \\
\hline D & 112,50 & & & \\
\hline E & 115,40 & & & \\
\hline $\mathrm{F}$ & 78,00 & & & \\
\hline G & 826,36 & & & \\
\hline $\mathrm{H}$ & 773,45 & & & \\
\hline I & RS $\quad 112,65$ & & & \\
\hline \multicolumn{3}{|c|}{ Volume of sales } & & \\
\hline RSU & $6.799,00$ & $24 \%$ & & \\
\hline RSP & $7.296,00$ & $25 \%$ & & \\
\hline DRSE & $6.735,00$ & $23 \%$ & & \\
\hline \multirow[t]{2}{*}{ DRB } & $7.918,00$ & $28 \%$ & & \\
\hline & $28.748,00$ & & & \\
\hline
\end{tabular}


Brazilian Journal of Operations \& Production Management

Volume 13, Número 1, 2016, pp. 44-50

DOI: 10.14488/BJOPM.2016.v13.n1.a4

Table 2 - Equilibrium Point and Equilibrium income of each DC analysis

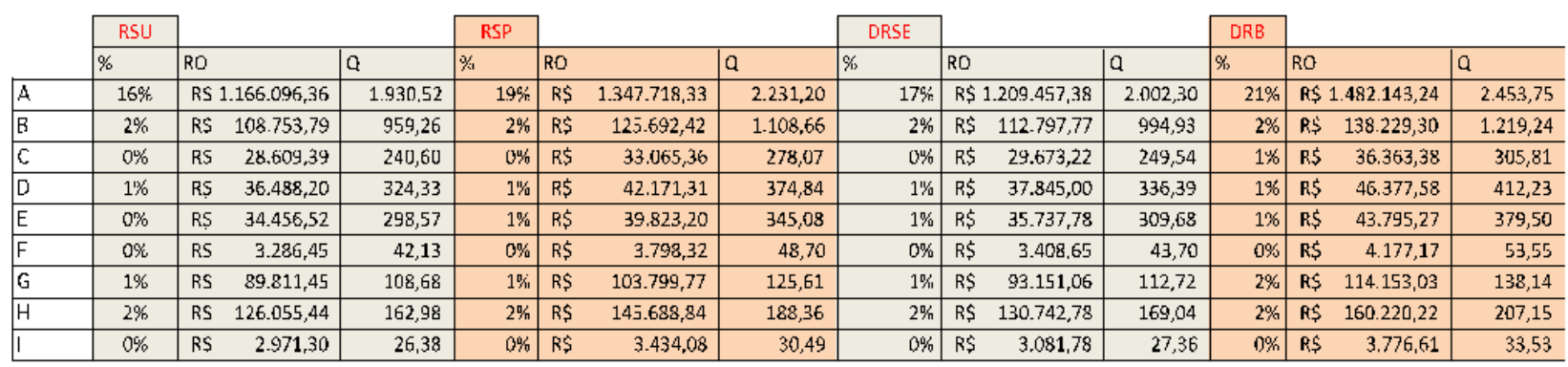

\begin{tabular}{|ll|}
\hline ROPOA & R\$7.126.851,75 \\
\hline
\end{tabular}

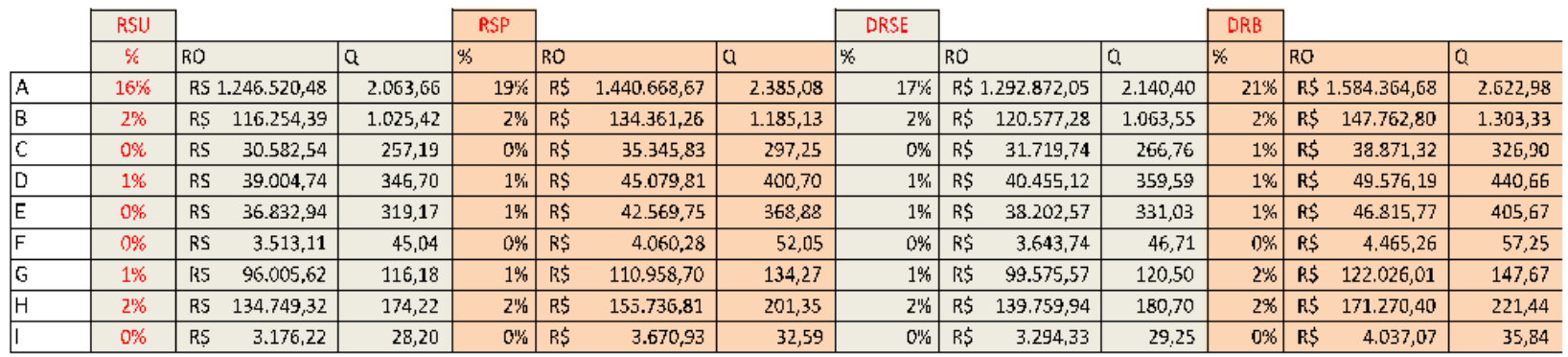

ROSP $R \$ 7.618 .381,22$

From the data calculated to each product in both scenarios, the Equilibrium Point for sales that would enable the São Paulo DC was calculated, as well as the current Equilibrium Point. Looking for the results is possible to see that the new DC in São Paulo (SP) will demand an increment in the income of the company. Than, these results were then compared with past sales from January to November
2014, in order to assess profitability with the DC in Porto Alegre versus the establishment of the new DC. Table 3 shows these results. This comparison is interesting, because the difference between the two alternatives is not big and maybe, some qualitative points could be considerated and influence the manager to install the DC in são paulo.

Table 3 - Profitability analysis using Equilibrium Point

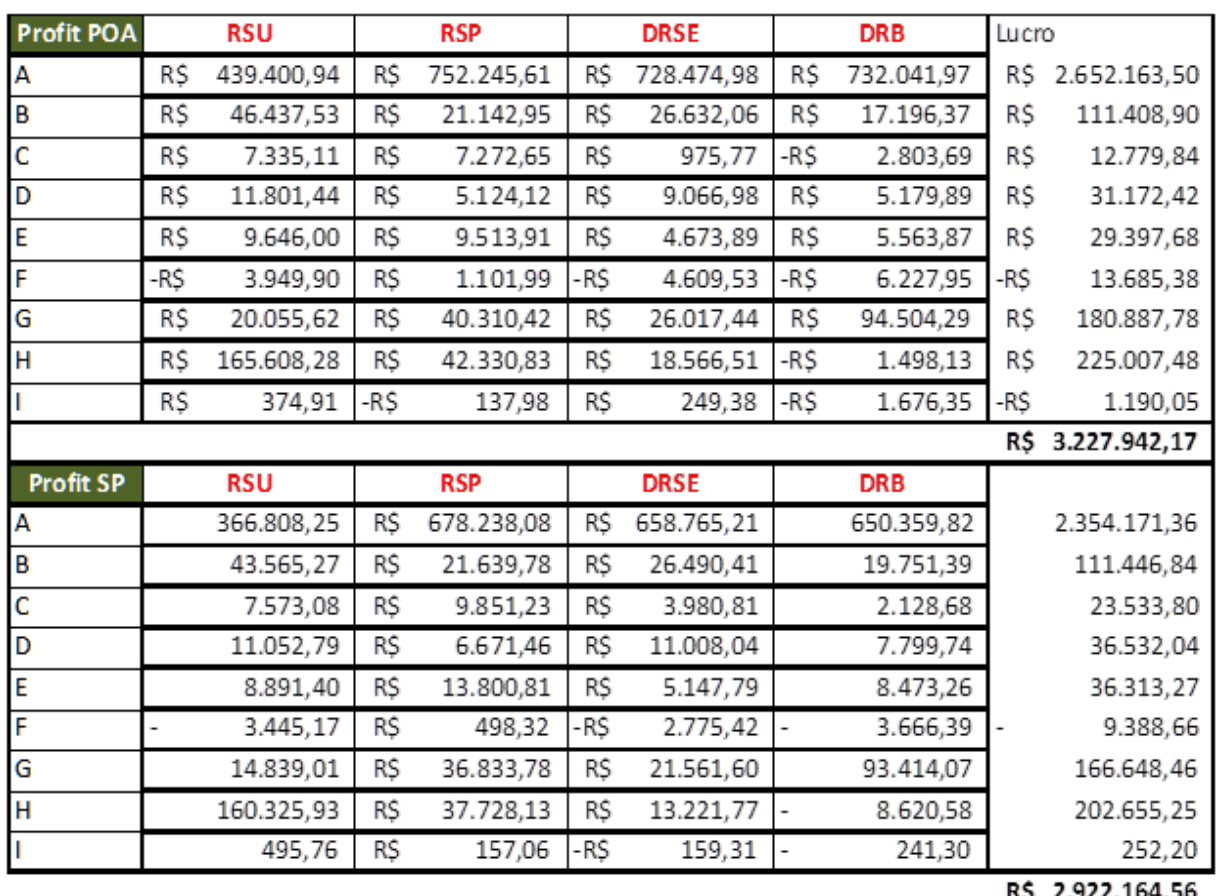


According to Table 3, the firm's profit is estimated to decrease R\$305,777.61 with a DC in São Paulo. Evidently, the financial analysis cannot be the sole motivation for top management decision making, but it provides a significant starting point for strategic considerations.

\section{CONCLUSIONS}

Logistic costs usually have a strong impact in a firm's cash flow (Ballou, 1999), without adding value to the products, and are considered one of the key wastes of the lean philosophy (Womack et al., 1992). Thus, managers and decision makers should pay close attention to the elements that influence, either positively or negatively, these costs, as they can be a significant source of variation of the firm's profitability. Besides, depending on the specific industry where a firm operates, market positioning strategies can be considered key strategic actions that drive the business towards better customer service.

In this context, the present paper reports a viability analysis for the establishment of a new DC for a company operating in the Brazilian radiopharmaceutial industry. The results include the minimum sales volume for each product and each region in order to financially justify opening a DC in a key market. The key result is the difference between the current profits and the estimated profits with the new DC, which can be used as a starting point for strategic decision making. Improved revenues from new customers due to the improved service level were not factored in the financial cost analysis, for instance.

The study also highlighted the importance of using cost analysis techniques, such as the CVP method, to study the financial impacts of logistic decisions. In particular, the case study reported in this paper illustrated how the expansion of logistic infrastructure impacts fixed costs, on the one hand, while provides a better position to reduce variable costs, given the closer proximity with selected customers.

Future research in this area of inquire should consider additional analysis techniques, such multicriteria tools that help researchers to capture qualitative criteria that influence decision making. Thus, financial results could be complemented with other factors that influence firm turnover. Techniques to associate financial values to qualitative assessment scales could also be employed to create a single, easy to understand and shared meaning for all decision makers.

\section{REFERENCES}

Ballou RH (1999) Business Logistics Management. 4th ed. Prentice-Hall, Upper Saddle River, NJ.
Boaventura EM (2009) Metodologia da Pesquisa: Monografia; Dissertação; Tese. Atlas, São Paulo.

Bornia AC (2010) Análise gerencial de custos: aplicação em empresas modernas. 3. ed. Atlas, São Paulo

Ellström, D. et al. Logistics cost management models and their usability for purchasing. 2011.

Engblom, J. et al. (2012) Multiple-method analysis of logistics costs. International Journal of Production Economics, v. 137, n. 1, p. 29-35. doi:10.1016/j.ijpe.2012.01.007

Fernandes BC, Galamba FH, Tosta LI, Lima RS (2011) Impactos da utilização de centros de distribuição na logística de distribuição de produtos acabados. Journal of Transport Literature, vol. 5, n. 3, pp. 163-181.

Gudehus T, Kotzab H (2009) Comprehensive logistics. Springer, Berlin.

Hill A (2003) - Centros de Distribuição: estratégia para redução de custos e garantia de entrega rápida e eficaz - 4a Conferência sobre logística colaborativa.

Horngren, T., Foster, D. M. Contabilidade de custos. 9. ed. Tradução José Luiz Paravato. Rio de Janeiro: LTC, 2000.

Moraes C, Wernke R (2006) Análise custo/volume/lucro aplicada ao comércio de pescados. Revista Contemporânea de Contabilidade, v. 1, n. 6, p. 81-101.

Ravichandran R (1993) A decision support system for stochastic cost-volume-profit analysis. Decision Support Systems, v. 10, n. 4, p. 379-399. doi:10.1016/01679236(93)90069-F

Stock JR, Lambert DM (2001) Strategic Logistics Management. 4th ed. McGraw-Hill Co, New York.

Waller MA, Fawcett S (2012) The total cost concept of logistics: one of many fundamental logistics concepts begging for answers. Journal of Business Logistics. DOI: 10.1111/j.0000-0000.2011.01033.x

Womack JP, Jones DT, Roos D (1992) A máquina que mudou o mundo.Campus, Rio de Janeiro.

Yoshizaki H, Ho L (2009) Collaboration intensity in the Brazilian supermarket retail chain. Supply Chain Management: An International Journal, v.14, IIS.1, pp.11-21. http://dx.doi.org/10.1108/13598540910927269 